\title{
The Influence of Social Environment on Victoria's Secret Advertising
}

\author{
Jiaxin Liang
}

\author{
University of Exeter \\ zbliangjiaxin@163.com
}

\begin{abstract}
In the era of big data, the social environment is developing every day, and without exception company social environment will issue corresponding advertisements in response to different social policies to increase the influence of publicity. Grier and Deshpande's article mention the theory of group identity. This theory shows that in a social group, group members take the group's goal as their ambition. The researchers illustrate that targeted advertising is the most effective and understands the society, because the impact on the uniqueness of consumers [4]. This research is aimed at Victoria's Secret Company's advertisement, mainly study the relationship between social environment and advertisement. Research the influence of social factors on advertising content by comparing the design of past advertisements and the current changes. This article will also study the propaganda model and the company's design philosophy and analyze the company's current situation, explore the problems encountered in the development of Victoria's Secret. The present research fundamentally used the research method of literature review and the author combined previous theories and data analysis to achieve the purpose of this research. Through analysis, it can be concluded that advertising change with adjustments in the social environment, and the social surroundings have impacts on advertising significance.
\end{abstract}

Keywords: advertisement, publicity, social environment, influence, consumption.

\section{INTRODUCTION}

In the change with new day time generation, people's concerns are constantly transforming. People's concerns are usually the focus of social big data the concerns of people are usually mainly about social big data, and these affect the company's promotional content. So now in life, most of people detect advertisements that are changing in accordance with social changes, such as using the most popular words in social media. This also leads people to think about the influence of the social environment on advertising design.

A few years ago, girls pursued a perfect image, however, now more people advocate being themselves, and no longer pursuing perfection become a new fashion trend. Being yourself is the most beautiful convert approved sentence in this time. These words are now enriching our lives and appearing on major social media networks. At the same time, advertisers also begun to change advertising design and advertising slogans. This phenomenon is thought-provoking, whether advertising is changed due to environmental changes in society. This research is to meditate the relationship between social environment and advertising planning, and the social environment affects the content of announcement. Through analysis, the author hopes to understand factors in the social surroundings will affect publicity. The author hopes to understand the factors in the social environment that affect publicity in the target market through analysis. This article will study Victoria's Secret's current advertising "be yourself" and compare the Victoria's Secret's "perfect body" with a few years ago, look up the reasons for changes and the impact of current advertising, it also would be concluded about the social environment have influence on advertising design. By considering the reasons for revolutions in advertising strategy, it could better apply the research results to the company's publicity department in the future, and it could understand the psychological impact of the social environment on people, which will help the company better understand consumers' consumption motives and reasons for consumption. 


\section{SOCIAL REVOLUTION}

\section{1 brand background}

Victoria's Secret is a company from the United States. The main products are women's underwear, as well as the production of various accessory clothing, swimwear, perfumes and cosmetics. In the past, Victoria's Secret focused on attracting male customers, but did not cultivate a large number of followers among women. After Wexner bought Victoria's Secret, he created a brand new for women, allowed women to realize their charm and extravagant fantasies. This new shopping environment create greater market demand. Victoria's Secret positions its main customers among teenagers and young women, because their production philosophy is to give customers beauty, romance and fashion. At Victoria's Secret company, they plan to develop a new underwear style every year. This strategy can ensure the brand's freshness and mystery for customers. The name of the company also has a special meaning. The word secret sounds mysterious, it caters to the mystery of underwear under the layers of people's clothes, bringing unlimited reverie to customers. Victoria's Secret advertising always focuses on showing the lines and charm of consumers, which arouses Chinese women's love for this brand. The company is hiring eminent models to become the spokesperson of the company's products, and holding a world-famous underwear show to attract the attention of consumers and non-consumers, as shown in Figure 1, this operation successfully attracted a large number of fans to start paying attention to Instagram of Victoria's Secret.

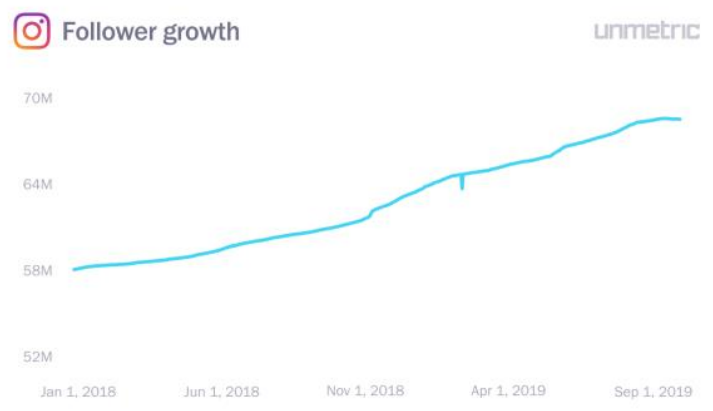

Figure 1 Instagram followers of Victoria's Secret

Grace Nichols described Victoria's Secret as fashion which is an integral part of the lives of many customers. Victoria Secret makes customers feel charm, beauty, fashion and a little romance. The company needs to know what fashion best suits women's physical and emotional needs. In the Victorian underwear show, brand culture is very important. The designer designs products that can show the charm of Victorian women in accordance with the Victorian style. Though SWOT analysis [7], the brand culture of Victoria's Secret is obvious and arduous to be replaced. The brand awareness opened in the early stage, and the company's internal sales plan is evident, such as launch a new underwear every year, which is accurate and tasteful for market and consumer positioning. However, for the brand's positioning of consumer groups, other potential consumer groups are ignored, and the company's design concept cannot fully summarize all consumers. For example, Victoria's Secret used models with wonderful bodies, nevertheless, they did not take care of girls with an imperfect body in the real life. In the future, there may be have consumer products with precise positioning, insist on holding Victoria's Secret underwear show to win consumers' attention. However, in the development of the company, the emergence of many competitors become a threat to Victoria's Secret. Because underwear is a popular product, many competitors appeared.

\section{2 social environment}

There are many social environmental factors, such as public opinion and people's living conditions. For this article, gender is an important factor. In this society, people have some stereotypes about girls. As the author of Negotiating Femininity said, girls always rely on boys' views and want to seek the recognition of boys [3]. This is what people often call ideal girls. However, for girls, there are no ideal girls and perfect girls, everyone is a beautiful existence. For example, a topic that is currently popular discussed in the society is appearance anxiety, it is a manifestation of people lack self-confidence. It is necessary to believe that everyone has unique beauty, and people should not blindly pursue popular aesthetics. The perfection is not necessarily objectively defined perfection, it can be subjectively considered perfection. For example, through efforts to achieve a thing that meets expectations or even exceeds expectations, even it is still inadequate in the views of outsiders, it can maintain that it is perfect. Persuasiveness is also one of the important factors in the social environment. Higgins and Walker's article illustrates the emergence of persuasive strategies that can promote social impact and help companies pursue sustainable development. At the same time, persuasiveness can influence people's behavior and thinking [6]. Social influence is hard to disappear in the world, and it changes at any time due to various factors, such as the direction of people's public opinion. Therefore, the brand awareness of the company opened in the early stage, and the company's internal sales plan is evident, such as launch a new underwear every year, which is accurate and tasteful for market and consumer positioning. It is encouraged to adapt to changes in the social environment and develop a positive social impact on the company. 


\section{BRAND AND SOCIETY}

In the past, Victoria's Secret always hired models with perfect bodies. the propaganda slogan which used in the advertisement is about the perfect body as well. Girls pursue the perfection determined by the world because of their devotion for the brand. Although in this process, the girls have a lot of pressure because of these perfect factors. In Jeon's article, it is pointed out that girls become somatization due to the pressure brought by perfectionism [5]. More and more people find that the requirements for girls in society are extremely harsh, and many women and even men begin to oppose such conditions. Therefore, Victoria's Secret also be greatly affected. from Victoria's Secret always aimed at perfection, and the models selected for the underwear show held every year are models with perfect bodies, as shown in Figure 2, the ratings of the underwear show held by the company dropped sharply.

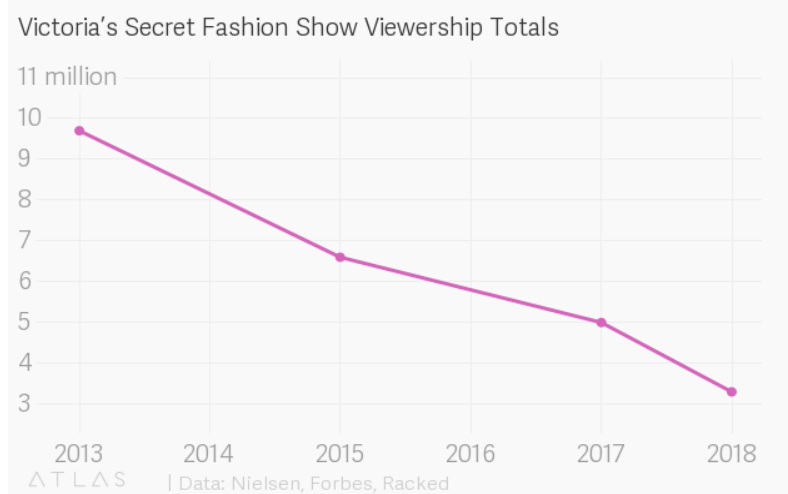

Figure 2 Viewing data of Victoria's Secret Underwear Show

In recent years, a strong competitor in Victoria's Secret appeared. Aerie is in line with the aesthetics of the current society. They hired various models of tall, short, fat and thin, and the models appearing in their advertisements are not handle. No retouching is to give consumers a more real consumption experience. These marketing methods used by Aerie also greatly improved women's sense of consumer identity. Not only Victoria's Secret and Aerie are affected by social factors, all enterprises will be affected by changes in the social environment. For example, in an incident in China some time ago, H\&M and many brands lost most of the market in China because they banned the use of Xinjiang cotton. A large part of the impact of this incident came from people promoting and boycotting these brands on social media. Therefore, after this incident, many brands' sales in China fallen sharply, and some stores are even facing the crisis of closing. There is also a publicity method commonly used by brands to hire high-traffic celebrities to become brand spokespersons, but if the spokesperson has problems and loses the market from their fans, the brand will also be affected. On the contrary, if the spokesperson gets higher traffic, the brand also gets more sales.

Regarding the social environment that is not conducive to Victoria's Secret, Victoria's Secret also made appropriate adjustments to its advertisements. Recently, the secretaries of Victoria in China announced their new spokespersons. They are five well-known celebrities. One of them is Yang Tianzhen, a famous Chinese celebrity agent. Her appearance broke the boundaries of the previous Victoria's Secret model. Her figure is not perfect, she does not have an excellent facial feature like other stars, but she endorses Victoria's Secret, and the new slogan of Victoria's Secret is "to be yourself". Yang Tianzhen's personal promotional photos also wrote "to be what you want". After this change, consumers also accepted that Victoria's Secret is more than just designing clothes for girls with perfect bodies. The research of Deepthi Gabriela and Choudhury depiction the perfect body in the Victoria's Secret "Love My Body" campaign advertisement is just a fabrication, because not every model is thin in order to achieve the goal of perfect body [2]. Through social comparison theory, comparing with others will affect one's body image[1] Through analysis, the author hopes to understand factors in the social surroundings will affect publicity. The author hopes to understand the factors in the social environment that affect publicity in the target market through analysis. After Victoria's Secret changed its marketing direction, it caused a heated discussion among consumers. Those girls with imperfect bodies can also buy Victoria's Secret products and gain confidence. However, some people think that Victoria's Secret broken the traditional practice and lost the traditional brand positioning.

\section{CONCLUSION}

It is concluded from this study that the social environment has an impact on the company's advertising content. In the case of Victoria's Secret, the company has a good profit effect when it is aesthetically appealing to the public, and when the advertising content does not conform to the social environment, it will be resisted by consumers. In the Victoria's Secret market, it has the advantages of personalization and brand influence, and it can also create opportunities by hiring new spokespersons and designing new advertisements. People cannot control the changes in the social environment, and public opinion always changed the requirements for girls. These brands that regard women as their main consumers can only constantly improve the company's strategy based on the current social situation. Advertising needs to cater to market changes in order to get better results. The current research still has some shortcomings. For example, the data does not carry out detailed statistics, and the research does not conduct experimental interviews with 
girls. Future research can add some real experimental steps can improve the authenticity of the research. Future research directions can focus on using changes in the social environment to improve the efficiency of advertising.

\section{REFERENCES}

[1] Chrisler, J. C., Fung, K. T., Lopez, A. M., \& Gorman, J. A. (2013). Suffering by comparison: Twitter users' reactions to the Victoria's Secret Fashion Show.Body image, 10(4), 648-652.

[2] Deepthi Gabriela, M., \& Choudhury, S. (2020). A semiotic analysis on the Victoria's Secret Love My Body Campaign advertisement.IJRAR-International Journal of Research and Analytical Reviews (IJRAR),7(1), 380-385.

[3] Duke, L. L., \& Kreshel, P. J. (1998). Negotiating femininity: Girls in early adolescence read teen magazines. Journal of Communication Inquiry, 22(1), 48-71.

[4] Grier, S. A., \& Deshpandé, R. (2001). Social dimensions of consumer distinctiveness: The influence of social status on group identity and advertising persuasion. Journal of Marketing Research, 38(2), 216-224.

[5] Jeon, J. H. (2015). Influencing Factors of Adolescent Girl's Somatization. Advanced Science and Technology Letters. Healthcare and Nursing, 104, 128-133.

[6] Higgins, C., \& Walker, R. (2012, September). Ethos, logos, pathos: Strategies of persuasion in social/environmental reports. In Accounting Forum(Vol. 36, No. 3, pp. 194-208). No longer published by Elsevier.

[7] Sarsby, A. (2016).SWOT analysis. Lulu. com. 